Session 3263

\title{
Experiential Learning in Computer Integrated Manufacturing Through Team Projects
}

\author{
Winston F. Erevelles \\ GMI Engineering\& Management Institute
}

\begin{abstract}
The paper describes projects undertaken by student teams in a senior level course in Computer Integrated Manufacturing. Students generate concepts for a product, synthesize this concept into multiple design alternatives, select the most feasible design based on manufacturability and assemblability considerations, manufacture the product on CNC machines in the CIM Laboratory, develop solutions for automated assembly, and implement software solutions for hierarchical supervisory control of manufacturing operations. Student teams (4-5 students each) are challenged by the complexity of the project, the need for extensive planning and teamwork based on project management principles, the interfacing required with vendors and in-house technical support, the need to interact and collaborate with 7 other student teams working on the same endeavor in the same laboratory, and the compressed time frame of the project.
\end{abstract}

\section{Introduction}

Computer Integrated Manufacturing (CIM) has been espoused, attempted, and implemented by various sectors of US industry in response to the challenges of an increasingly competitive global market. An examination of CASA/SME's LEAD (Leadership and Excellence in the Application and Development of CIM) award winners yields industries from different areas of the manufacturing sector. Each of the winners has demonstrated manufacturing excellence through integrated solutions achieved by multifunctional, interdisciplinary teams. Over the past few years it has become increasingly obvious that functional isolation and the barriers between different functional areas of an organization jeopardize their competitiveness and even survival. Initiatives such as Profile 21 and Curricula 2000/2002 have identified needs and deficiencies in manufacturing education and have made recommendations for programs at various levels of education and experience ${ }^{\mathbf{1 , 2}}$. At GMI, these initiatives and industry's needs have resulted in a drive towards integrated manufacturing curricula featuring a continuum of experiences that enable students to correlate subject matter learned in different courses. Snapshots of localized information are thus synthesized into a fabric of engineering knowledge and interpersonal skills that are applicable to a variety of manufacturing problems and situations in the workplace. The goal here has been the provision of realistic experiences that would enable participants to develop and refine technical, interpersonal, and communication skills 3 Projects undertaken by student teams lend themselves very nicely to such a goal.

\section{Overview of GMI and the CIM Facility}

GMI Engineering\& Management Institute has long been regarded as America's premier co-operative college. Students alternate between full time academic experiences and co-operative experiences in industry for a period of 5 years as part of the engineering curriculum at the baccalaureate level. The diversity of 
industrial backgrounds among the curriculum majors brings a wealth of experiences, ideas, and insights when it comes to problem solving in the classroom. This makes student project work an exciting and rewarding endeavor for the students, the faculty, and technical support personnel.

One of GMI's most prominent laboratories is the Computer Integrated Manufacturing (CIM) laboratory. This facility provides undergraduate students with a sophisticated environment in which they can learn about, experiment with, and conduct projects and research activities in CIM. The laboratory is part of the Industrial and Manufacturing Systems Engineering (IMSE) Department and supports classes in NC Systems, Robotics, and CIM. The industrial grade facility features an AS/RS, an AGV, twelve robots, machine vision, Auto ID equipment, five CNC machines, Allen Bradley Programmable Logic Controllers, conveyor systems, twelve 486-based personal computers, three Sun IPX's, a Spare 10, and a Spare 20. The laboratory was recently endowed by the addition of a PLC-controlled magnet assembly line from Weldun International, Inc. The equipment is configured into cells for material storage, material handling, machining, and assembly. The facility is based on the NIST- AMRF (National Institute of Standards and Technology - Automated Manufacturing Research Facility) hierarchy, and uses supervisory computer control techniques to integrate the various cells. Currently the facility uses CIManager - a Microsoft Windows-based automation software package from CIMULUS, Inc. and CELLworks - a UNIX-based enabling software for workcell control from FASTech Integration, Inc. for this purpose. Fourth Shift - an MRP-based manufacturing management software package from Fourth Shift Corporation is being integrated with the CIManager software in some of the cells in order to integrate all functions related to the production process.

\section{Overview of the CIM Course}

The CIM course runs twice a year in the Summer and Fall terms with about 48 students at the Senior level. Over a twelve-week term the students are exposed to the various components of CIM systems through multimedia lecture sessions and laboratory exercises. The class meets thrice every week for hour-long lecture sessions and once a week for two hours of laboratory work. Lecture sessions are supplemented by various assignments. Laboratory exercises are supplemented by mini-projects for each laboratory exercise and a term project that provides a view of the "big picture" by requiring students to integrate the core areas of competence that they acquire over the duration of the term.

Lectures sessions address Computer Aided-Design, Group Technology, Computer Aided Process Planning, Numerical Control, Robotics, Integrated Manufacturing Planning and Control, Process Monitoring and Control, Communication Nets and Protocol Standards, CIM Models and Concepts, and Planning and Implementation of CIM Systems to mention a few topical areas. Laboratory exercises include robot programming using GMF and IBM robots, PLC programming using Allen Bradley equipment, material handling using a Litton AGV, CAD/CAM using Mastercam software (or the choice of AutoCAD, I-DEAS, or Unigraphics), CNC machining on a Kryle Vertical Machining Center (VMC), Supervisory Control using CIManager software, and Manufacturing Management using Fourth Shift software. These provide students with the background they need for the term project.

\section{The Term Project}

\section{Objective:}

Students are expected to learn the operation of various components of the CIM laboratory, and then take a product from an initial concept all the way to actual production while integrating various cells in the facility. Students will thus acquire skills in applying the principles of concurrent engineering and integrating manufacturing systems. In addition they will develop/refine interpersonal, team, and communication skills. 


\section{Team operation:}

Student teams are formed with 4-6 students per team with leaders who are elected or volunteer for the job. Team leaders are responsible for their assignments within the group, and are also required to coordinate activities within the team, ensure adherence to the Gantt chart developed by each team, communicate problems/issues to the consultants, and ensure the timely delivery of progress reports. A GMI co-op (the term is used to describe students who spend a term working in a selected laboratory as part of the co-operative experience) may serve as the project coordinator to ensure compliance with the overall timeline developed for the term. The CIM Lab technician and the author serve as consultants to all teams.

\section{Project description \& scope of work:}

Student teams are required to develop a product that can be manufactured in the CIM laboratory using existing facilities. Product development is undertaken using brainstorming and Concurrent Engineering techniques. Manufacturability and assemblability considerations are of paramount importance at this stage due to the nature of the hardware being used, and the sharing of the hardware with 8 other student teams working on different products.

The design process is followed by the development of the Bill of Materials (BOM) to decide upon make/buy issues and exporting the CAD files to Mastercam for the generation of NC part programs. Two and three-dimensional toolpaths are created in Mastercam in preparation for the CNC machining phase of the project. These toolpaths are verified in Mastercam, post processed, and downloaded to the Kryle VMC using serial links. Graphical verification is undertaken on the Kryle to ensure a safe and accurate machining cycle, and this is followed by the actual machining of the product/components. The teams develop and fabricate the fixtures for the assembly of their products. They also design, machine, fabricate, and install the necessary "fingers" on the robot end effecters used in the CIM Lab. This stage takes some planning and co-ordination among the various teams and ultimately results in sets of inserts in order to accommodate different product configurations. Students then develop robot programs for assembly and teach all necessary points. The final stage involves the development of supervisory control flowcharts using the CIManager software. While teams are given the option of integrating several operations (e.g. the robots, the AGV, and Fourth Shift MRP software etc.), they are expected to demonstrate supervisory control of the assembly process at the very least.

The work of each team is documented in detail in a final report. This report includes the problem statement, team assignments, the plan of attack, Gantt chart (old and revised), a brief description of procedures, and accurate and complete documentation of work done

\section{Grading:}

Project work accounts for $25 \%$ of the overall course grade. The project grade is based upon the following factors: complexity of the project; overall quality of the work to include all steps pertaining to the design, manufacture, and level of systems integration; the planning and implementation of projects; and the quality of the documentation and final presentations. Final presentations and project demonstrations are videotaped to assist in grading process. Peer grading on a confidential basis is factored into the term project grade to help reflect the work (equitable load sharing and the quality of the work) done by each team member. 


\section{Teaching CIM Using the Project Approach - Lessons Learned}

1. Buy in from all participants is necessary for a successful project. Students from past CIM classes have been motivated by the opportunity to integrate and apply the knowledge acquired in several courses to a real world situation.

2. Be prepared to invest significant amounts of time. A project such as the once described above is not a trivial undertaking for the students, faculty, or staff. Communication and planning are key ingredients for success.

3. Project planning is of utmost importance to ensure project completion on schedule, within planned costs, and with the human resources that are allocated at the initiation of the project.

4. Interpersonal problems arise in any group of individuals - discussions in an informal setting help resolve some of these issues. This serves as a valuable exercise in conflict resolution.

5. Dealing with slackers - be prepared to step in and ensure compliance with overall plans. This may have to be done on a couple of occasions early on in the project.

\section{Conclusion}

Team projects in CIM enable students to plan a system from the top-down and then work on its implementation from the bottom-up. The synergy of technical, interpersonal, and communication skills provides students with a learning experience that is superior to isolated experiences targeting the individual. The project continues to be a very rewarding experience for the students, the instructor, and the supporting staff and has led to the development of products including a multi-level tetrahedron, a cooler, desk set, a jewelry box, a three-dimensional maze, puzzles, a diablo (juggling device), a CD rack, and a clock facade.. Student comments on evaluations mention "high levels of motivation", "pride in project work", and the "infusion of the real world into the classroom".

\section{Bibliography}

1. Koska, D.F. and J.D. Romano "Countdown to the Future: The Manufacturing Engineer in the 21st Century”, A.T. Kearney Research Study, Profile21, Executive Summary, SME, Fall 1988.

2. Arthur, A. A., D. Wells, and P.J. Demers, "Curricula 2000 Workshop Proceedings: Ideal Models in Manufacturing Education", SME, February 1990.

3. Bordogna, J., Fromm, E., and Ernst, E.W., "Engineering Education: Innovation Through Integration", Journal of Engineering Education, ASEE, January 1993, Vol. 82, No. 1.

\section{Biography}

Dr. Winston Erevelles is an Assistant Professor of Manufacturing Systems Engineering at GMI Engineering \& Management Institute. His teaching and research interests are in the areas of CIM, Robotics, and Manufacturing Systems. He has a B.S. in Electrical Engineering from Bangalore University, India, and M.S. and Ph.D. degrees in Engineering Management from the University of Missouri-Rolls. He has worked as a Service Engineer and Plant Manager at Mykron Engineers, India. He is an active member of SME, ASEE, and AAAI 